\title{
Imagine Home: Making a Place in Binghamton
}

\author{
Aynur de Rouen ${ }^{1}$ \\ Binghamton University, New York, USA
}

\begin{abstract}
Since the early 1990s, Iraqi Kurds have been relocating to the greater Binghamton area in New York State. This study focuses on the growing diasporic Kurdish community in and around Binghamton and their quest to imagine the homeland they left behind as a result of social, economic, and political hardships. Existing literature heavily emphasizes Kurdish diaspora in Europe as the main impetus for the Kurdish refugees' social and political issues, neglecting to also recognize communities in the United States and North America. This study aims to fill this gap by analyzing how the production of the diasporic space has emerged as an attempt to reconstruct Kurdish culture and collective identity in the absence of physical and territorially specific aspects of their homeland. Kurdish refugee narratives articulate how collective memory gives voice to a shared Kurdish past, how Kurdish refugees appropriated the space according to their traditional example and kinship structure, and how memories and narratives of the past shape the migrants' identities, kinship, and everyday practices. The production of diasporic space within the imaginations of these refugees is portrayed here to show their attempt to reconstruct Kurdish culture in the absence of the physical characteristics of their homeland. Their successfully reinvented images of homeland and reconstructed culture in diaspora are evidence of the resilience and fluidity of Kurdish culture.
\end{abstract}

Keywords: Kurdish diaspora, United States of America, migration, memory, space, narrative.

\section{Introduction}

My journey to document Kurdish culture and history began when the Binghamton University Libraries received a donation from the children of the late Dr. Vera Beaudin Saeedpour, who started the Kurdish Library and Museum out of her home in Brooklyn, NY, in the early 1980s. The collection is a significant assemblage of materials documenting Kurdish history and culture. During an event where the collection was first introduced to the public in September 2011, I was approached by several Kurdish students and learned of the relatively large Kurdish presence in and around the Greater Binghamton area in New York State. I began spending time with them and hearing their remarkable stories of persecution in Kurdistan and of their migration to the United States. As I was listening to their recounts, I realized that no one had told the story of their plight, either in Binghamton in particular or in the U.S. in general. In fact, not many people knew of the Kurdish struggle, or even who the Kurdish people were until recently. This particular silence and elision of diasporic lives propelled and legitimated the creation of the Kurdish Oral History Project at Binghamton University.

The research presented here has largely been based on informal interviews with Kurdish refugees from Dohuk and its surrounding villages, who have been living in Binghamton for almost two decades. Each of these refugees holds memories of events surrounding their lives back in Kurdistan. Some lived through the events themselves, while others recalled the memories of their parents and relatives. This study provides insight into the ways diasporic living always involves intimate and many different kinds of attachments to their homelands. In particular, it is an attachment that in many ways is negotiated through war and trauma. The lives of Kurds in Binghamton demonstrate the complex process of diaspora formation where aspects of cultural traditions and kinship structure play a pivotal part in both local and transnational claims to space and place.

As key source material, oral history is the main tool for this study to explore how memory is articulated, given meaning, and collectively negotiated across generations and spatial locations. Collectively, these oral history narratives reveal what the interviewees think, perceive, imagine, and remember about their homeland. Oral histories play a very important part in diachronic understandings of time. "Analysis of narrative research relies on a type of diachronic data, the storied narrative. The storied narrative differs from a mere listing of a sequence of events, that is, from a chronicle.... The sources of storied narratives are varied ... Interviews appear to be the most often used source of storied narratives in contemporary narrative inquiry" (Polkinghorne, 1995, p. 12). While investigating the

${ }^{1}$ Correspondence; E-mail; atderouen@ gmail.com 
formation of the diasporic space in their new surroundings through interactions, family structure, and kinship configuration, my principal interest in this study has been to articulate how their experiences at home and the images of Kurdistan are negotiated and managed in diasporic settings. At the same time, it shows the effect these images hold in the process of constructing diasporic space in Binghamton through examinations of interpretations of both individual and collective memory.

\section{Memory and Space}

This study examines space as a social phenomenon and emphasizes that memories of traumatic past and collective memory practices are both linked to the social production of space (Lefebvre, 1991; Shukla, 2003; Thangaraj, 2015). In my usage, "space as a social phenomenon" refers to the spatial relationships that exist between people, experienced in the minor details of daily life in the physical space. Thus, this study depicts how Kurdish refugees of Binghamton reproduced their space according to their needs and how they modified the diasporic space through interactions, family structure, and kinship configuration.

While scholars from various disciplines agree that space is worthy of exploration, it is defined in varying ways according to a number of methodological frames (Altman \& Setha, 1992; Schindel \& Colombo, 2014; Tuan, 1977). For this project, Henri Lefebvre's theoretical framework, The Production of Space, is the most helpful in understanding this concept. His work explores fundamental questions of how and why space matters as a social representation and emphasizes that "space is a product," arguing that it is the production of space that provides parameters and relations within a society (Lefebvre, 1991, p. 26). According to Lefebvre, space is produced through a spatial triad: the perceived-conceived-lived. This well-known triad guides the present study. The analysis of the production of urban space is formulated not only as a part of physical reality, but as part of the political nature of planning, social interactions, and mental constructs, as well.

This research also depends upon various interpretations of memory on the individual and collective levels. The work of Maurice Halbwachs, in this regard, is useful to examine the concept of collective memory. Halbwachs, who emphasizes the social context of memory, asserts that memory is contingent upon the function of the mind in society and that the operations of mind and memory are structured by social arrangements (Halbwachs, 1992). ${ }^{2}$ By exploring how the mind works in society, we not only understand how individuals deal with their personal traumatic and nostalgic memories, but also how they exploit them as collective reference points for their group. Thus, social frameworks express and decipher the contents of collective memory, which include shared facts and experiences pertinent to the group. Memories, which are shaped in society through relationships and social arrangements, not only help communities to remember but also enable them to retain their own identity and become salient examples of their collective memory, thus strengthening ethnic consciousness, as is the case in this study. This argument is applicable to this study, especially when involving a task or activity that is performed collectively, i.e., festive events such as weddings, picnics, religious holidays, and even everyday small gatherings.

Cultural historians stress the persistence of society over individual memory in their analysis of collective memory (Kansteiner, 2002; Lafer \& Tarman, 2019; Schudson, 1995). They argue that collective memory is constructed historically and socially; it exceeds the significance of personal memoirs. This study stresses the importance of collective memory, yet also emphasizes that personal narratives are key sites to negotiate collective memories (Green, 2015). Memories are rarely "personal" and "raw," but shaped in and by social and historical processes. When dealing with the relationship between memory and space, both the individual and collective experiences of space occupy people's memories, and we find that the latter is more significant in reflecting one's relation to the space (Dewi, et,al, 2018; Johnson \& Hinton, 2019).

This study embraces Halbwachs' arguments that individuals do not remember coherently and persistently outside of a group context. Group memberships, such as family, ethnic groups, and social classes, provide the materials for memory and stimulate the individual into recalling (or, in some cases, forgetting) particular events (Boyer, 1994). According to Halbwachs, when individuals recall collectively, they locate those memories in connection with the social context in which they lived (1992). ${ }^{3}$ This argument is particularly relevant to this study, due to the level of group involvement required in negotiating self across various temporal and spatial registers: memories of war, conflict, and

\footnotetext{
${ }^{2}$ Halbwachs calls individual memory personal and autobiographical memory, and mémoire collective (collective memory) social and historical memory. Social memory is the memory of things that an individual experienced personally; conversely, historical memory spreads out to groups and communities, and can function to reconstruct the past.

${ }^{3}$ Halbwachs argues that collective memory is constructed and bequeathed by a group and is derived from group-related ideas, which are shared through traditions, myths, stories, rituals, and images. For Halbwachs, every person composes a memory, which is socially mediated and derives from the group. Every individual memory - created through communication with people who share a common image of their past, i.e families, neighborhoods, associations, and political parties - is incorporated within the larger collective memory.
} 
resistance, and festive events such as weddings, religious holidays, and commemorations of events. The refugees I interviewed shared these moments of post conflict and social interactions, and used them to define themselves as a group and underline their belonging to a single nation.

In light of the aforementioned theories, I will first explore the ways in which these Kurdish refugees continue to live and imagine space, specifically in their homeland post conflict. Second, following Lefebvre's theory that every society produces its own space and uses space as a tool to reflect their collective memories, I will analyze how space is modified post conflict, namely in the Kurdish diaspora in Binghamton. Third, I will argue that the creation of a diasporic community in Binghamton that follows the example of Kurdish tradition and kinship structure seems to be connected to the Kurdish identity via memory and everyday practices.

\section{Setting the Scene}

The Kurds are recognized as the largest non-state nation that has faced physical pressure, violence, cultural assimilation, and ethnic cleansing in the Middle East. Today, around 25 million Kurds live in Turkey, Iran, Iraq, Syria, and parts of the former Soviet Union. As a result of various forms of Turkification, Persianization, and Arabization, over one million Kurds have dispersed all over the world and built diasporic communities (Hassanpour \& Mojab, 2005).

Diasporas have been in existence for millennia - long before the Kurds began to settle around the world. The word diaspora is derived from the Greek verb $\delta \imath \alpha \sigma \pi \varepsilon i \rho \omega$ (diaspeirō), meaning scattering. The term originally described displacement of peoples from their homeland as a result of traumatic events, such as the Jewish expulsion from Jerusalem to Babylon in 586 BCE (Cohen, 2008; Shain \& Barth, 2003). ${ }^{4}$ In this study, I look at the outward migration of the Kurds from Iraqi Kurdistan (South Kurdistan) to the United States.

Starting in the nineteenth century, Kurds began to migrate first to Europe (Alinia, 2004; Keles, 2015; Wahlbeck, 1999), and then, by the end of World War I, their path shifted toward the United States (van Bruinessen, 2000). ${ }^{5}$ However, the first significantly large wave of migration to the U.S. occurred in the early 1990 s after the horrific Halabja and Al-Anfal campaigns, which caused approximately 65,000 Iraqi Kurds to flee to Turkey (Wallbeck, 1999). After spending time at the refugee camps in either Iran or Turkey, some moved back to Iraqi Kurdistan while those who secured their passage to the West arrived in Europe before making their way to the U.S. ${ }^{6}$

The emergence of Kurdish diaspora in the Greater Binghamton area began in the mid-1990s after Saddam Hussein's invasion of Kuwait. Economic, social, and political issues in 1996 contributed heavily to many Kurds leaving their homeland behind and beginning their migration to the United States (Gunter, 2008). Thousands of Iraqi Kurds with ties to western agencies first fled to Turkey and were almost immediately relocated to Guam by the U.S. They remained in Guam for three to six months until their resettlements were arranged. Among these Kurdish refugees, some chose to settle in Binghamton due to strong kinship links as many of their family members and friends settled in the area following the Anfal campaign. ${ }^{7}$ The following excerpt sums up their journey to the U.S.:

Back then many Kurds worked for NGOs in the Kurdistan region and Saddam Hussein was threatening anybody who worked for American NGOs. Because of this, the United States decided to pull everybody who worked directly or indirectly for them. Approximately five to six thousand Kurdish people left Kurdistan. After staying a couple of days in Turkey, we flew directly to Guam. At the end of our three-month stay there, we were asked if we had any relatives in the U.S.; if not, they would choose our new destination for us. We had some relatives living here since 1992, so we chose Binghamton as our new home (A. Amin, personal communication, March 22, 2013).

Binghamton soon became a destination site and a possible new homeland, located at the confluence of the Susquehanna and Chenango Rivers in New York State's Southern Tier region. Historically, Binghamton constitutes a site of settler colonialism with early settlers arriving by the early 1800s (Roediger, 2014). The village became a city in 1867 , and today it comprises 11.14 square miles $\left(28.9 \mathrm{~km}^{2}\right)$ in Broome County with the 2010 census reporting the

\footnotetext{
${ }^{4}$ According to Yossi Shain and Aharon Barth, diaspora represents "a people with common origin who reside, more or less on a permanent basis, outside the borders of their ethnic or religious homeland-whether that homeland is real or symbolic, independent or under foreign control" (2003, p. 449).

${ }^{5}$ After World War II, they also started fleeing to neighboring countries, as was the case after 1974/75 when 50,000 Iraqi Kurds fled to Iran.

${ }^{6}$ The time they spent at the refugee camps varied as some informants mentioned; some stayed several months while others acknowledged spending years in those camps.

${ }^{7}$ According to the records of the Kurdish Regional Government Office in Washington, in 2015 about 70,000 Kurds lived in the United States and more than 500 of these refugees lived in Binghamton.
} 
city's population to be 47,376 (Smith, 2006; United States Census Bureau, 2016). Refugees have had considerable impact on the local population in Binghamton since 1983. According to the report from the Brookings Institution regarding the trends in refugee resettlements in the U.S., 1.6 million refugees resettled in the U.S. between 1983 and 2004, and Binghamton is listed as a small metropolitan area with a high refugee-to-foreign-born ratio (Singer \& Wilson, 2006). Binghamton, with $9.4 \%$ of its population comprised of foreign-born citizens, has been welcoming ethnically diverse communities for decades, and is home to sizeable Ukrainian, Bosnian, Iranian, Vietnamese, and other refugee communities (United States Census Bureau 2016). Kurdish refugees continue to arrive in Binghamton, today.

\section{Methodology}

This research relies heavily on personal in-depth interviews with both male and female Kurdish refugees between the ages of 18 and 65, all of whom reside in the Binghamton area. So far, forty-eight in-depth interviews have been conducted either at respondents' residences, which allowed me to observe their current domestic setting, or in my office at Binghamton University when home-visits were not possible. As Linda Shopes asserts, "an interview is above all a social interaction" (1996, p. 234). Thus, in the comfortable and relaxed setting of their own homes, the informants felt more at ease and were more engaged and revealing about their experiences, treating me as a friend or relative. As is customary in Kurdish tradition, when I visited their homes, they treated me with various offerings, ranging from a simple cup of tea to well-prepared meals. This tradition allowed us to exchange information and get to know one another better. I was not only able to conduct more detailed interviews, but also to build a trusting relationship with them, which paved the way for them to return for additional interviews. Each interview session lasted a minimum of two hours, and involved an interviewer sitting down with one or two interviewees at a time. Interviewees were asked questions pertaining to their life in their place of origin, their culture, their families, how they constructed their lives in diaspora, and the oppression they faced.

These refugee families are currently residing outside of their homeland, thus our project draws influence from Halbwachs' assertion that "it is in society that people normally acquire their memories, and it is also in society that they recall, recognize, and localize their memories" (1992, p. 38). When these refugees were asked to compare the communities in which they lived in both Kurdistan and Binghamton, almost every respondent generated idealized images of the homeland that have become embedded in their collective memory. Collective images of the past and ultimately a desire to return to Kurdistan reveal longing and collective needs. They remembered, imagined, and described Kurdistan. They answered questions by cultivating a portrait of the past, and, in part, by delving into their life experiences both in the homeland and in diaspora while holding onto their collective memory.

Contrastingly, without socially relevant family and friends, memory often recedes and the details of past lives cease to exist in the conscious mind. This approach has provided me with a methodological and theoretical theme: that both public and private space, as well as social life, are fundamental to the construction and preservation of memory (James, 2018; Harvey, 2006). Places are not just in the physical landscape; they also appear in individuals' minds, customs, and bodily practices (Low, 2003). Memory, whether individual or collective, plays a significant role in the formation of space through remembering past events, reviving facts, and recalling previous experiences. This is how one relates to place both physically and mentally as is the case for the diasporic community in Binghamton. By remembering and visualizing homeland, these actors point to personal memories, occupying space, and modifying Binghamton into a Kurdish place. For example, celebrating Newroz or commemorating Halabja helps these refugees to generate knowledge and foster the Kurdish identity. Space keeps memory alive and, in this case, respondents are remembering Kurdistan - whether they were working in the field, attending school, hiding in the mountains, or trying to survive in refugee camps - and tell us about their culture, everyday life, and political and social history.

\section{Remembering Homeland in Diaspora}

The narrative prior to diaspora reveals the intertwining relationship between harsh living conditions and struggles of survival. The shared memories of Iraqi Kurdistan that many of the Kurdish refugees vocalized during the interview sessions illustrate the prevalence of violence and fear in their everyday lives. The Kurds in Iraqi Kurdistan have suffered the most under Saddam Hussein and the Ba'ath regime. With the Ba'ath Party's rise to power in the early 1960s, Kurds were either killed or forcibly moved to other parts of Iraq and their lands were taken from them as part of the Arabization policies (Chaliand, 1994). Thousands died as a result of systematic atrocities against Kurds, beginning with a series of Kurdish rebellions and harsh retaliations from 1963 until the First Gulf War in 1991 (Meiselas, 1997; Vanly, 1993; Wahlbeck, 1999). These narratives, which were historically silenced by the powers in charge, teach us that the war and conflict have left deep scars. The following account further illustrates the difficulties Kurds encountered under the Ba'ath regime: 
For the past three decades prior to 1991, you were living under a dictator. You had to obey him, you had to speak his language, and you had to do everything that he wished... As part of Saddam's ethnic cleansing he did not recognize that the Kurdish people existed... When I was young, I remember coming home from school every day and my parents having to deal with crisis after crisis: there was either new extended family or relatives that were discovered, or a new family member had disappeared and no one knew where they were taken, or a new village where our relatives used to live had been bulldozed and we didn't know where they had been relocated to (K. Zebari, personal communication, June 10, 2013).

This vignette points to the difficult times many of the informants shared during our interview sessions. As vocalized in this testimony, disappearances, torture, and arbitrary arrests under the Ba'ath regime were common. Witnessing what was happening to his relatives and listening to his parents' conversations clearly made this respondent realize as a child that the Ba'ath Party was full of hate against Kurds and did not believe in any Kurdish rights. Children grew up with the notion that any relationship with the government was one of trauma, violence, and marginalization, and the whole family could face condemnation. They witnessed the disappearance of whole families overnight without any explanation. Numerous respondents confirmed that many had to pretend to support the Ba'ath Party in order to protect their families. Their narratives strongly emphasize that the Ba'ath Party was killing them for no other reason than their Kurdish identity. These events and instances of unknown whereabouts of family members and fellow Kurdish neighbors became embedded in children's personal memories that they now share with the new generation, effectively contributing to the construction of collective memory.

Avras, one of seven children in his family, remembers growing up in Dohuk in the 1990s. He remembers his house, his family, and playing with his friends. He recalls sharing both the physical and social space with the members of his extended family:

I remember home, dirt roads, brick houses... that's where the city was, where I was born and raised. We used to have a big house where four or five families lived in it. Imagine the house is just another big house where each room is considered a house for a person or each room is considered a house for a family member. I remember they cooked separately for each family, and whenever there was a special event or a holiday then we would cook together and have a big meal all together... I remember playing soccer with my friend a lot on the dirt roads if we had a ball. Sometimes my cousins and I would just wander in the marketplace. My dad owned a small grocery store. We would see what fruit he had, and we would pick an apple or orange even if we were not allowed... I loved Eid. I would go to every family member to celebrate Eid and then they would give me candy and money and they would give me some kisses; I was looking forward to it all because I would be rich that day (A. Taha, personal communication, November 1, 2014).

Like most narrators, Avras remembers his childhood by reminiscing about his house, family, pastimes, and family relations, and his oral history is representative of some Kurdish refugees' stories, as they share their experiences of trauma and loss. While admitting to the trauma of life in South Kurdistan, memories also become sites of feeling, joy, happiness, and other aspects of community building that did not revolve around just violence. The narrative reveals that the family relations, everyday spatial practices, and social interactions with relatives and neighbors played a vital role in shaping inhabitants' childhood memories. These refugees negotiate to modify the diasporic space by subdividing houses into individual homes in order to continue to live under the same roof, or they move to homes in close proximity to each other so they can remain relatively close. These spatial strategies emphasize the literal togetherness of family.

Since the majority of the narrators are from the Dohuk area (which is predominantly Kurdish), the narrative does not offer memories of how Kurds and Arabs interacted. Yet, the collective history offered by some of the interviews suggests that some degree of social interaction took place between the communities even though boundaries of identity were crossed relatively conservatively, as represented in the interview below:

I still remember our house in Baghdad. The environment was kind of friendly and everyone was treated with respect. The good thing about Baghdad was your neighbors were your family. The neighborhood was mixed: Kurds, Arabs, and Christians. One 
of our neighbors, Osman from the Dilemy tribe - a huge Arabic tribe in Baghdad always helped us. One of his sons was an officer in Saddam's army and every time there was a problem and whenever Saddam was looking for Kurdish people, he would tell us. He always tried to help Kurds... We used to go to his house for dinner and he would come to our house for dinner or lunch (A. Ameen, personal communication, March 8, 2013).

Saddam's Arabization and discrimination policies affected every aspect of Kurdish peoples' lives and their relations with Arabs. It is clear from this account that the respondent's family developed a reciprocal and personal relationship with their neighbor, despite the state's assimilation policies towards Kurds. However, the majority of respondents from the Dohuk area confirm that contact between the two groups was limited. Other than simply greeting each other, there was no connection. They acknowledged that the only Arabs living in their neighborhood were government employees who worked for Saddam. Kurds typically kept their distance from them as they were afraid that they spied on them. As testimonies reveal, people used to visit neighbors outside of their own ethnic or religious groups; some remember their interactions and even the names of their old neighbors. Their narrative illustrates nostalgic moments shared between minority and majority groups.

\section{Modification of Space}

The importance of family and friends and the traditional premise of homeland constitute an integral part in Kurdish refugees' lives since their arrival to Binghamton in the early 1990s. Building a community in a host land is not an easy task, as individuals bring their own cultural practices from the homeland and those they have encountered through travel and migration (Clifford, 1994). The narrative points out that, upon their arrival, people started to modify their notion of home, which is shaped by kinship structure. According to Stuart Hall, diasporic people are individuals who "belong to more than one world, have more than one language (literally and metaphorically), inhabit more than one identity, have more than one home; who have learned to negotiate and translate between cultures, have learned to live with, and indeed to speak from difference" (1995, p. 206). It should be noted that this study provides insight into socially coded spaces and activities, particularly the transformation of private space. It does so by examining the role of boundaries in the social network among family members, relatives, and neighbors. The narrative captures how these individuals experience space, their relationships to this newly constructed place, and how they negotiate their roles within the host community, with one another, and with outsiders. Drawing from oral testimonies allows me to describe diasporic living and how it fits into the needs of these refugees who were still tied to their traditions.

The majority of my respondents emphasized the importance of being surrounded by other Kurds and/or surrounding themselves with culturally relevant objects, smells, and sounds. The construction of collective memory also involves the social production of space, installation of meanings, and engagement with cultural artefacts. Upon their arrival, some lived in the same apartment complex or on a nearby street, but in general, they seemed to share the same neighborhood. Almost every respondent remembered their initial arrival to the area and how they shared the space with each other as it is described here: "About seven families came in 1992. All of us Kurdish people lived in the same building over on Main Street in Johnson City. We all lived there. We always went out and saw each other, you know?" (A. Amin, personal communication, March 22, 2013). Just like Amin, other respondents gave details of how they appropriated the living space into a multi-purpose space. For example, by throwing a mattress for the boys on the living room floor, some families turned their space into a two-bedroom apartment. During the daytime, women used the space for food preparation with their Kurdish family members and neighbors, and then as a bedroom during the night. This close proximity shows how Kurdish refugees negotiated a shift from homeland to host-land and, in most cases, rural to urban, and how they appropriated that space. This arrangement allowed these refugees to inscribe their Kurdish identity on their lives, while sharing space within an American community and having a supportive, immediate network on which to rely. As Kurds held historically-based skepticism of states, self-help and communal support were critical in diasporic settings. Organizations like the American Kurdish Council, New York Chapter, and American Civic Association help introduce the newcomers to American society by acquainting them with the health system, employment agencies, language schools, etc. Members of the Kurdish community, on the other hand, helped their fellow refugee friends with every aspect of the diasporic setting, from translating documents to driving them to grocery stores.

The premise of Kurdish family here is based on the multi-member and multi-generational household. In addition to sharing the house with extended family members, testimonies point out how married couples were added to the household after marriages. In this context, when sons of the family got married, they continued to live with their parents in the same house and were obligated to take care of the family while the women stayed home and ran the household. Hierarchy is established with the elderly male as the head of the family, and it is evident in the narrative 
that the hierarchical rules are still well accepted and respected. In diaspora, however, while some of the newlywed couples set up their own space, first generation migrants, who are more traditional, continued to live with their older sons and their immediate families under the same roof. This represents these refugees negotiating modernity by maintaining traditional kinship structures while living in diaspora. It also allowed them to negotiate American life through financial measures such as splitting up rent by multi-generational and multi-family living. Social status also manifested in the size and the spatial positioning of the houses, and the degree to which the houses' interiors were decorated. Many newcomers live in low-income housing because this is one of the ways in which refugees are settled by the immigration authorities. Refugees who are more fluent in English and established in the host society obtained professional jobs and tend to live in middle-class residential neighborhoods in multi-level houses with large gardens.

Younger generation Kurds who arrived in the U.S. as children enculturated into American norms through their consumptive practices, which is evident in their choice of furniture, clothing, education, and how they carry out their social lives. In most cases, the houses I have visited were furnished with upholstered couches and armchairs, coffee tables, and an informal dining table with chairs and large pillows scattered around the floor. During the interview, the younger generation always sits at the table or on the couch, while the older generation prefers to sit on the floor to eat and perform other activities. It is remarkable that eating habits, as an important aspect of collective memory, seem to have continued to shape domestic life in the new living space that had once only been bound to home, in Kurdistan. This example also indicates how the young generation integrated into the host society and adapted patterns of everyday life in their new surroundings. The following excerpt describes how they maintain their tradition when it comes to the transformation of domestic space:

It is similar, very similar. We still sit on the floor, we still eat on the floor, and we still make the same dishes. We all sit on the floor instead of the couch and just drink tea and talk. But there are differences: there is a big TV, there is nice furniture, it is warm. I mean there are both similarities and differences. We try to remember our roots and who we are and what we are and not to change anything, especially when our young ones are coming up and then see what we are. We have tables, but we still eat on the floor and we still put on Kurdish clothes. At home, my mom, my sisters, and my sister-in-law still wear that long dress that you see Kurdish people back in Kurdistan wearing. So yes, there are a few similarities when you come to my house that make you think this is not an American house! (A. Taha, personal communication, November 1, 2014).

This testimony represents the continuity of tradition, while at the same time showing how some refugee families modified their houses according to their needs. We see cultural citizenship at play where these spatial methods of living expand the contours of American-ness while affirming "Kurdishness" at the same time (Maira, 2009; Thangaraj, 2015). What we see are acts of place-making and the transformation of spaces into Kurdish places. These refugees used cultural artifacts to decorate their living rooms where they welcome their relatives and friends. The furniture, carpet, and even ornaments showcased their enactment of the Kurdish culture. In The Spirit of the Folk Art, folklorist Henry Glassie argues that homes are our mirrors and they reflect the inhabitant's identity, which is manifested through the material culture, i.e., the domestic furnishing in the living room (1989). These refugees were able to transfer the sustainable cultural aspects of Kurdish traditions into their diasporic settlement in Binghamton, manifesting in areas from the decoration such as rugs, doilies on coffee tables, colorful fabrics covering shelves, metal pitchers, trays, and ceramic cups, as well as the arrangement of their houses to the landscaping of their backyards. These artifacts, such as rugs, fabrics, and bags, represent the Kurdish culture through their dyes, weaving techniques, and motives. Next to upholstery, metal objects are other valuable items in most of the interviewee's house. Metalsmiths have worked among Kurds for generations, and each piece carries techniques and designs that are intrinsic to Kurdish culture.

It is also evident that these refugees' use of space is mapped onto the physical fabric according to social codes. The Kurdish public space is reconstructed to respond to the need of the diasporic setting. There are a number of festivals, religious events, and commemorative events that are celebrated by the Kurdish refugees, such as Ashura (the commemoration of the killing of Imam Huseyin), Newroz (the Kurdish new year festival), Eid-al-Fitr Feast (End of Ramadan), and Eid-al-Adha' Feast (the Feast of the Sacrifice). These events expand and transform the use of physical space in which the refugees bind the social with the spatial.

During festive events, elderly men always sit together while older women sit with their family members. Both genders in younger generations share the public space with not just their relatives and friends, but with non-Kurdish people as well. However, when they dance during weddings, they still abide by the rules where girls do not hold hands 
with male members of the community unless they are next of kin. The patriarchal hierarchy and sense of gender segregation are evident among some Kurdish groups, as it had not always been practiced this way.

The Badini tradition is to separate between genders. But not all families! When we visit some families we sit in the living room all together; men on one side and women on the other. But we all talk to each other, and if there are no men to serve the guests food and drinks, then a woman does. In other families, there are separate rooms for men and women. But it is strange because in those families, men and women sit together to eat with the guests, then they separate again for tea and coffee or whatever is being served later on. In Sorani families, however, there is no separation. Gender segregation in Badini families here in Binghamton, however, might not be true for families who know each other, such as if they are acquaintances (M. Tawfiq, personal communication, February 18, 2016).

This testimony offers evidence of how social interactions between men and women belonging to the different Kurdish tribes transform in diaspora. It is clear here that the members of the Badini tribe modified social and spatial implications of gender-based segregation in domestic space. It has been observed both during various interview sessions and Kurdish events I have attended in Binghamton that kinship structure coordinates closeness between men and women. This testimony also points out the importance of the hospitality structure in Kurdish culture. Even in households where segregation is very strong, if the male member of the household is not present, a female member takes on the role of host to uphold proper formalities, demonstrating the role of hospitality as a highly valued aspect of their culture.

For the first generation refugees, Kurdish cultural codes are adapted into the diasporic space even further. Because of their language limitation and job status, the older generation was more restricted in their new homes. Men tended to venture out more frequently than women, by either visiting each other at their homes or making regular visits to mosques and local Kurdish shops where they could drink tea and talk about politics and everyday life. Women who stayed home went outside only when accompanied by the younger generation. Unlike their mothers, the younger generation girls followed the contemporary lifestyle by going to school and, after graduating, finding jobs.

Regardless of their generation and gender, the narrative illustrates that these Kurdish refugees value community, to which they feel a sense of belonging and connection, which also helps them locate and more regularly engage with their memories. The majority of testimonies, as is seen in this respondent's account, emphasize their longings for celebration: "Eid was the best thing, to be honest. Even right now we still miss those days" (Z. Taha, personal communication, February 22, 2013). This shows how a space is transformed into a Kurdish place by reconfiguring time. Instead of celebrating Christian and U.S. national holidays as the most important days, they celebrate Newroz and Eid as a way to use the contemporary temporal moment to imagine the past. This interviewee is not alone in articulating his feelings. Many described gathering for Newroz and Eid celebrations as the most joyful times:

I remember celebrations for Eid and Newroz...We had all type of picnics. A couple weeks ahead of time, all the family gets together - let's say about ten or fifteen families with cousins, uncles, aunts - and decide who is going to cook what and what type of vegetables and fruit we will bring and where we are going. Then that day, we get up in the morning whether it's sunny or raining or even snowing (A. Ameen, personal communication, March 8, 2013).

These instances of collective remembering help individuals transcend their cultural identities to construct a strong sense of communal bonding in diaspora.

The social sphere is another dimension of the collective memory, mentioned by almost every interviewee (Halbwachs, 1992) ${ }^{8}$. Here, the social sphere corresponds to the concentration of interactions that comprise an ethnic group. Accordingly, the general social sphere expands or contracts depending on the varying levels of communication and interactions. Increasing seasonal activity, interaction with friends and family, population growth in diasporic community, and so forth, for example, might increase the breadth of a social sphere while reinforcing particular individual and collective memories. Most of the narratives that were conveyed to me relate the social sphere, social

\footnotetext{
${ }^{8}$ According to Halbwachs, the term collective memory describes the communal store of shared experiences and memories that members of social groups acquire over a period of years as they interact with each other. Based on Halbwachs's work, this study applies the term collective memory to the social sphere of memory.
} 
values, and the traditional codes, such as affection and respect, which build the connections among a community, as well as hospitality and mutual respect for religious beliefs and gender segregation. The narrators also discussed the aspects of everyday life, which are significantly different in a diasporic setting, such as the close social ties among individuals for which they expressed their nostalgic longing. The findings confirm that space is also a site for affective economies where feelings are negotiated and managed. In the process, affect provides a platform for constructing a wide variety of memories. The idealization of the homeland was evident in the narrative even though not all aspects of the homeland are missed, such as persecution, poverty, poor health, economic problems, and especially the loss of their loved ones. Additionally, not all imaginings of the homeland are shared during the interview sessions, such as family feuds or the level of privacy at homes due to multi-member occupation. Regardless of their generation and gender, the majority of the informants wanted to convey a sense of harmony as a community by focusing on joyful memories; however, certain silences suggest that the household was not always free of problems and conflicts. Yet, these refugees are still capable of holding onto their "Kurdishness" and continue that identity through future generations. No matter how many decades they live in diaspora or how much they integrate into the host society, when asked, the answer will always be "I am first and foremost Kurdish." Thus, by constructing a space in which these refugees can connect with their relatives and fellow Kurds, sharing their past struggles and presenting the Kurdish identity to the host society becomes a pivotal task. Preserving Kurdish identity is no easy task for these refugees since American identity, enculturation, and various forms of assimilation can so easily take over through schooling, work, and social activities (Sharifi \& Sheyholislami, 2014). ${ }^{9}$

In our interviews, the older generation seemed to convey that they do not like American society. The narrative depicts self-dependency as one of the fundamental characteristics of American society, which is not usually the norm of Kurdish culture. Their experiences in the U.S. are managed and mediated through their (essentialized) conceptualizations of "Kurdishness" and culture. These elders invoke "Kurdishness" as a category to manufacture differences between generations and between national spaces. They are consciously attempting to preserve their culture and religious tradition by trying to convince their American-born relatives to follow in their footsteps. Some members of the younger generation of refugees keep the Kurdish tradition alive by teaching their American-born children the language and cultural and religious practices shared by the majority of the Kurdish refugees living in the area. The narrative shows that Kurdish refugees are trying to sustain continuity between the traditional Kurdish culture and modern Western materialism by projecting their imagined Kurdistan onto the diasporic space of Binghamton.

\section{Conclusion}

This study articulates how the diasporic space is reconstructed through interactions, family structure, and kinship configuration by Kurdish refugees of Binghamton, New York, while, at the same time, demonstrating how their previous experiences in their homeland help them to flourish in their new endeavor. This research is also concerned with the role of their images of Kurdistan in the process of formation of diasporic space in the host country by examining various interpretations of memory on the individual and collective levels. This work also provides understanding of these Kurdish refugees' efforts to construct a diasporic space as their new homeland and what it means to them, but, more specifically, captures the imaginations of these people who are currently lacking the social markers: what made them Kurdish.

Collective memory was also used to construct the history of traumatic events resulting in experience of loss. Memories of hardship caused by wars and harsh treatment were further intensified by the loss of the loved ones intertwined with their feelings of nostalgia, specifically associated with social gatherings and kinship relations. In an effort to create a space that allows them to establish a sense of belonging while connecting to their homeland through culture, kinship, and politics, they established a very close-knit community in the Binghamton area.

The efforts of these refugees to share their experiences and their collective past from Kurdistan with the younger generation helps maintain the continuity of their "Kurdishness" in the host country. Most of the narratives that were conveyed to me relate to the social sphere, social values, and traditional codes, such as affection and respect. Other frequently covered topics included maintaining the patriarchal family structure and preserving their religious customs and rituals, socialized roles, and gender segregation. This study proposes that it is likely that Kurdish refugees will remain keen about passing on their culture to future generations. Based on the narrative, this study advocates that, although first-generation Kurds live in an individualistic society like the U.S., they continue to remain largely collectivistic - especially in regards to socio-cultural aspects that consist of ethnic identity, religious beliefs, food habits, and language in their newly constructed diasporic community.

\footnotetext{
${ }^{9}$ Amir Sharifi and Jaffer Sheyholislami presented evidence of the rapid loss of fluency in parental languages among the second and third generation of Kurdish migrants in the San Francisco area.
} 


\section{References}

Alinia, M. (2004). Spaces of diasporas: Kurdish identities, experiences of otherness and politics of belonging (Unpublished doctoral dissertation). Göteborg: Sociologiska Institutionen.

Altman, I., \& Low, S. M. (1992). Place attachment (Vol. 12). New York: Plenum Press.

Ameen, A. (Personal communication. March 8, 2013).

Amin, A. (Personal communication. March 22, 2013).

Boyer, C. (1994). The city of collective memory: Its historical imagery and architectural entertainments. Cambridge: MIT Press.

Cohen, R. (2008). Global diasporas: An introduction. New York: Routledge.

Chaliand, G. (1994). The Kurdish tragedy. London: Zed Books Ltd.

Clifford, J. (1994). Diasporas. Cultural Anthropology, 9(3), 302-338. http://dx.doi.org/10.1525/can.1994.9.3.02a00040

Dewi, I , Nababan, M , Santosa, R , Djatmika, - . (2018). The Characters' Background in the African-American English Dialect of The Adventures of Huckleberry Finn: Should the Translation Retain It?. Journal of Social Studies Education Research, 9 (4), 382-402. Retrieved from http://dergipark.org.tr/jsser/issue/43626/534268

Glassie, H. (1989). The spirit of the folk art: The Girard collection at the Museum of International Folk Art. New York: Abrams in association with the Museum of New Mexico, Santa Fe.

Green, A. (2004). Individual remembering and 'collective memory': Theoretical presuppositions and contemporary debates. Oral History, 32(2), 35-44.

Gunter, M. M. (2008). The Kurds ascending: The evolving solution to the Kurdish problem in Iraq and Turkey. New York: Palgrave Macmillan.

Halbwachs, M. (1992). On collective memory. Chicago: University of Chicago Press.

Hall, S. (1995). New cultures for old. In D. Massey \& P. Jess (Eds.), A place in the worlds. Oxford: Oxford University Press.

Harvey, D. (2006). Spaces of global capitalism: Towards a theory of uneven geographical development. London: Verso.

Hassanpour, A., \& Mojab, S. (2005). Kurdish diaspora. In Encyclopedia of diaspora. (Vol. 2, pp. 214-224). New York: Springer.

James, K. (2019). The Stagnation, fall and rise of Singapore's Political Opposition, 1996-2013. American Journal of Qualitative Research, 3(1), 37-56. https://doi.org/10.29333/ajqr/5810

Johnson, C., \& Hinton, H. (2019). Toward a Brillant Diversity. Journal of Culture and Values in Education, 2(1), 5670. Retrieved from http://cultureandvalues.org/index.php/JCV/article/view/27

Kansteiner, W. (2002). Finding meaning in memory: A methodological critique of collective memory studies. History and Theory, 41(2), 179-197.

Keles, J. Y. (2015). Media, diaspora ad conflict. London: I. B. Tauris.

Lefebvre, H. (1991). The production of space. Cambridge: Blackwell.

Shopes, L. (1996). Using oral history for a family history project. In D. K. Dunaway \& W. K. Baum (Eds.), Oral history: An interdisciplinary anthology. New York: AltaMira Press.

Lafer, S., \& Tarman, B. (2019). Editorial 2019: (2)1, Special Issue. Journal of Culture and Values in Education, 2(1), i-v. Retrieved from http://cultureandvalues.org/index.php/JCV/article/view/34

Low, S. M. (2003, February). Embodied space(s): Anthropological theories of body, space, and culture. Space \& Culture, 6(1), 9-18.

Maira, Sunaina. (2009). Missing. Durham: Duke University Press.

Meiselas, S. (1997). Kurdistan: In the shadow of history. New York: Random House.

Polkinghorne, D. E. (1995). Narrative configuration in qualitative analysis. In J. A. Hatch \& R. Wisniewski (Eds.), Life history and narrative. London: The Falmer Press.

Schindel, E., \& Colombo, P. (2014). Space and the memories of violence: Landscapes of erasure, disappearance and exception. New York: Palgrave Macmillan.

Shain, Y., \& Barth, A. (2003). Diasporas and International Relations Theory. International Organization, 57(3), 449479. https://doi.org/10.1017/S0020818303573015

Sharifi, A. \& Sheyholislami, J. (November, 2014). The role of heritage language in identity construction among diasporic Kurds in the United States. Paper presented at Middle East Studies Association (MESA) Annual Meeting, Washington, D.C.

Schudson, M. (1995). Dynamics of distortion in collective memory. In D. Schacter (Ed.), Memory distortion: How minds, brains and societies reconstruct the past. Cambridge: Harvard University Press. 
Shukla, S. R. (2003). India abroad: Diasporic cultures of postwar America and England. Princeton: Princeton University Press.

Singer, A., \& Wilson, J. H. (2006). From 'there' to 'here': refugee resettlement in metropolitan America. The Brookings Institution, Living Cities Census Series 2, 1-31.

Smith, G. R. (2006). Partners all: A history of Broome County. Virginia Beach: The Donning Company Publishers.

Taha, A. (Personal communication, November 1, 2014).

Taha, Z. (Personal communication, February 22, 2013).

Tawfiq, M. (Personal communication. February 18, 2016).

Thangaraj, S. (2015). Desi hoop dreams: Pickup basketball and the making of Asian American masculinity. New York: New York University Press.

Tuan, Y. (1977). Space and place: The perspective of experience. Minneapolis: University of Minnesota Press.

United States Census Bureau. 2010 Census State and County Quickfacts. Retrieved from https://www.census.gov/quickfacts/fact/table/binghamtoncitynewyork,US/POP010210.

van Bruinessen, M. (2000). Transnational aspects of the Kurdish question (Working paper). European University Institute, Florence: Robert Schuman Center for Advanced Studies.

Vanly, I. S. (1993). Kurdistan in Iraq. In G. Chaliand (Ed.), A People without a country: The Kurds and Kurdistan. New York: Interlink Publishing Group, Inc.

Wahlbeck, Ö. (1999). Kurdish diasporas: A comparative study of Kurdish refugee communities. New York: St. Martin's Press.

Zebari, K. (Personal communication. June 10, 2013). 